\title{
Political Communication vs Cultural Approach to Society Related to the Handling of Covid-19
}

\author{
Jounadi Kaseem ${ }^{1}$, Aish Zhain ${ }^{1}$, Kduoh Al Deen ${ }^{1}$ \\ ${ }^{1}$ Fa Political Science Faculty, Lebanese University, Lebanon \\ Received: July 5, 2021 \\ Received in Revised: August 20, 2021 \\ Accepted: August 28, 2021
}

\begin{abstract}
This study discusses political communication and cultural approach in handling the Covid-19 pandemic. Existing cases are taken into account along in the discussion of this paper to illustrate how measures like communication by political figure influence the Covid-19 mitigation. The cultural relevance of the COVID-19 community engagement message is critical to its effectiveness. Culture-insensitive communication may be seen in the COVID-19 case study as well as in the Ebola information being communicated. It is nevertheless important to recognize that a culture's collection of signals regarding life experience may range from positive behaviours that should be promoted to negative practices that should be addressed.
\end{abstract}

Keywords: Political Communication, Culture, Approach, Covid-19

\section{Introduction}

Covid-19 was met with both positive and negative feedback early on in its existence. While a few people are beginning to be cautious and make better health choices, many others show little concern, acting as if this disease is a joke. There is a viral epidemic that is causing considerable harm, and many authorities are completely ignorant of the fact that it is occurring. Even regular citizens seem to be oblivious to the problem. Despite Covid-19 spreading to many nations and getting in the way of people leaving, the government and its inhabitants seemed calm and didn't take any precautionary measures against this virus (Rudan, 2020).

Actually, there are less individuals who don't care about the development of the Corona virus than there are who want to keep it from emerging. But their apathy is what puts the virus in motion. The majority of individuals in this group believe they are infallible and see science as incorrect.

The Corona virus' uncertainty, perplexity, and urgency is sure to be stressing for a lot of individuals. Many individuals are upset, and specifically those in the middle class, because of their uncertainty about what the future holds due to the uncertainty of the epidemic's end date. People in the developing world can't get basic needs if they are not employed. For the majority of individuals, the danger of the Corona virus, with its potential to cause serious strain, is as terrifying as the actual virus itself.

The Terror Management Theory is supported by the fact that humans naturally dread death and the inability to predict when it will occur (Dunaetz, 2020). As a result, many human behaviours are motivated by the need to survive. The appearance of Covid-19 further intensifies the horror. People are expected to resort to both good and bad habits in order to stay alive.

There are many ways to make the community more optimistic throughout this epidemic; doing them will benefit the community by reducing its fear (Tavares et al., 2020). Worry for the impoverished has grown as individuals have donated money and assisted in fundraising efforts (Bin-Nashwan \& Al-Daihani, 2020). This has done so because many people who still manage to fulfil their daily requirements have raised their concern. Other organizations also assist in 
making and distributing Personal Protective Equipment for healthcare professionals and make huge numbers of masks to give to those who need to work in places where there is still exposure to diseases. People have been adopting healthier lifestyles out of fear of the Corona virus.

Additionally, Covid-19 is influencing individuals to behave selfishly just to live. For example, the fear of running out of items led to many a panic-purchase. Many people engage in panic purchasing and stockpiling basic needs like water because they cannot handle the stress of dealing with the unknown of the Corona virus (Bentall et al., 2021) We hoard because we're scared to leave our homes, which are a natural outcome of isolating ourselves because we fear being infected with Covid-19.

Instead of being motivated to purchase items they need, people become more obsessed with making purchases to have in their possession in case of need. In reality, these kinds of decisions would affect other individuals who live in poverty and will have a tough time finding enough food and goods. Additionally, some unscrupulous parties have also abused the phenomena of panicked purchasing by jacking up prices on products and getting away with it by committing fraud.

\section{Crisis Communication}

Covid19 pandemic was very difficult to deal with because of a variety of complicated issues stemming from things that typically aren't relevant to crisis communication research (such as political, economic, and sociocultural aspects).

Some crises, like this one, are even more difficult to foresee than other crises. We understand that it is a coronavirus, but this does not really help us since this virus is novel and therefore impossible to anticipate. Even if we could see it, there is a portion of the population that it does not affect. Despite the worldwide scientific community devoting a huge amount of time to researching Covid-19 in real time and putting out every attempt to develop a viable therapy as quickly as possible, the immense level of ambiguity about this virus and its effects is troubling. Due to the fact that there is no vaccine for the virus, the most we can do to determine the end of the pandemic is speculate and extrapolate, which makes the society and economy hesitate to go back to normal until the situation is really under control.

As Furthermore, the exposure of some countries' health care systems to a multitude of individuals with the Covid-19 infection who were in need of hospitalization exemplifies that these nations' health care organizations are lacking preparation and ability to face a pandemic. The recent surge in suicide was most severe in Europe, although the United Kingdom's health services were among the first to be significantly harmed by austerity. But this issue was caused, in part, by these nations being very slow to respond to the crisis. As was the case with Greece and Portugal, who suffered comparable austerity measures, having to also cope with a rapidly aging population, they took time to prepare their health systems and their people to combat the outbreak and allow it to peak in the future. They must have known early on that their health systems wouldn't make it through the height of the crisis if they didn't do something, so they took action. However, the methods and timing of each country's reaction differs, and the effectiveness of the measures is still up for debate.

Finally, the illness made clear the need of accounting for cultural variables in particular, such as the populace's adherence to quarantine policies. For example, in Southern Europe, whose cultures are known for warm welcomes and hugging, it is easy to find people who have given up these practices in their personal lives, in order to seem more professional in public. Citizens' behavior is influenced by historical, political, and cultural variables. In addition to differing lifestyles and traditions, the citizenry tends to follow their beliefs (that is, whether they support or reject the government). Lock-down measures, as for example hospitalization, were accepted 
as a motivational tool for Greeks to think about health instead of economics (Comite, 2020). In the Greek culture, the health of citizens was very important. In the research on crisis communication, there has been little attention paid to these elements.

Finally, the need for comprehensive and coordinated responses to such crises has highlighted the vulnerability of populations and economies in addition to the vulnerabilities that are built into society. The Covid-19 virus highlighted inequalities and the need for cohesive international action in the face of crisis (O'Connor et al., 2020). In this case, it's been especially relevant for the subjects of how poor people and working class citizens have to contend with difficulties such as reduced access to healthcare, housing conditions, and the effects of lockdown on poor people and working class citizens.

Fifth, in addition to intense media attention and false news being circulated on social media, crisis management agencies had to face a complex problem of the government's credibility suffering and growing mistrust in public institutions. We have to place a high priority on communicating openly and having a dialogue with the public, considering it a trustworthy partner. We also had to undertake the dangerous task of dismantling Covid-19's rumors, which had grown to include almost all of social media, in order to safeguard the public.

The last problem this worldwide epidemic has shown is a failure of international and regional bodies to coordinate their responses to the crisis. The increase of geopolitical tension and rivalry for healthcare resources has instead frequently resulted in the construction of an overly simplistic dichotomy between good and evil rather than fostering unity and a consensus approach to confront the crisis. A lack of consensus among the EU's most powerful countries has contributed to the delay in addressing the problem. They had to rely on China and Russia for supplies of medical equipment and trained medical personnel to treat patients with severe symptoms. A shift in how we think about and research crisis communication would be greatly aided by Covid-19 Pandemic as it presents a chance to re-evaluate how we conceptualize crises.

\section{Reflecting to political communication in Covid-19 handling}

The large number of existing cases has served as a lesson for other governments to take into consideration. The following case illustrates how political communication affects society, specifically how India failed to provide adequate prevention to the second wave.

\section{India Case}

Announcing important elections in five states where 186 million people were eligible to vote for 824 seats, India's electoral officials revealed the results at the end of February. In the state of West Bengal, the elections will be conducted in eight stages beginning on March 27 and lasting for a month, beginning on March 27. Campaigning had started in full swing, with no safety procedures in place and no social separation from the public eye or ears. In mid-March, the Indian Cricket Board permitted more than 130,000 spectators, the vast majority of whom were not identified, to attend two international cricket matches between India and England at the Narendra Modi stadium in Gujarat, which was largely empty.

It took less than a month before everything started to fall apart. India was in the throes of a catastrophic second wave of the virus, and cities throughout the country were being forced to remain closed. By the middle of April, the nation was seeing an average of more than 100,000 cases per day. On Sunday, India reported more than 270,000 cases and more than 1,600 fatalities, both of which were new single-day records for the country. According to a study by The Lancet Covid-19 Commission, if the runway infection is not addressed, India may be recording more than 2,300 fatalities per day by the first week of June. The research was released in response to a request for comment. 
Even India's massive immunization campaign was experiencing difficulties. At the outset, the deployment was mired in a debate about the effectiveness of a candidate who was developed in-house rather than imported. Despite the fact that the government increased its vaccination efforts and had given more than 100 million doses by the end of last week, vaccine shortages were observed. The Serum Institute of India, the country's - and the world's - largest vaccine manufacturer, said that it would not be able to ramp up supply until June due to a lack of funds to increase production capacity. Because the doses of the Oxford-AstraZeneca coronavirus vaccine were required immediately in India, the government temporarily halted all exports of the vaccine and permitted importation of foreign vaccines from other countries. Even oxygen was expected to be imported at this point in order to satisfy the increased demand.

As a result, experts now believe that bragging about India's "defeating" the pandemic - due to a younger population, local immunity, and a mostly rural population - and proclaiming triumph over the virus was tragically premature. As is customary in India, government hubris, hypernationalism, populism, and a healthy dosage of bureaucratic ineptitude have come together to produce a crisis that has lasted for months (Kumar, 2020).

India's second wave was fueled by people letting their guard down and attending weddings and social events, as well as by the government sending conflicting messages by permitting political rallies as well as religious meetings in the same place. As illnesses declined, fewer individuals sought vaccinations, resulting in a slowdown in the vaccine campaign, which had hoped to inoculate 250 million people by the end of the month of July.

It's possible that a second wave was unavoidable, but India might have prevented or at least delayed it, thus reducing its effect. India, like many other nations, should have started rigorous genomic monitoring in January to identify variations. Instead, the country waited until February. Some of these variations may be the ones responsible for the increase. Was there a lesson to be learned from this public health crisis? For starters, India should learn not to proclaim victory over the virus too soon, and it should keep its sense of triumphalism under control. People should also get used to brief, local lockdowns in the case of future outbreaks of illness, which will unavoidably occur. Given that India is still far from achieving herd immunity and that its vaccination rate is still low, the majority of epidemiologists anticipate that there will be further waves.

\section{Brazil Case}

Brazil is one of the most frequently-infected countries with COVID-19 globally. The Federal government has put new measures in place for all 26 states and the Federal District (known as Brasília) since the first case was discovered in São Paulo on February 25. These measures include travel restrictions, tax increases, mass layoffs, credit facilities, openings to foreign investment, social distancing, and new financial aid programs.

However, the Bolsonaro Administration is using a political discussion to make the seriousness of the outbreak in Brazil unclear. It's drawn criticisms from media, people, and the international community, as well as from certain state governments that prefer to keep federal guidelines more optional.

The treatments for several diseases, such as malaria, yellow fever, smallpox, and even Chagas disease, were led by Brazilian figures like Oswaldo Cruz and Carlos Chagas, who used the knowledge they gained from their research in Brazil to do so. "The World Health Organization said Brazil was a leader in the fight against HIV," according to the Associated Press (WHO). It's also worth noting that Brazil was the first country to provide universal health coverage in the post-OECD era, having already introduced this constitutional mandate in the Unified Health 
System back in the 1980s. Brazil has global recognition for its National Immunization Program, and its research into the Zika virus recently took the lead (Abbink et al., 2018).

It is unclear why the Brazilian Ministry of Health has decided to do little in response to COVID19. However, this might be because of internal political conflicts fueled by authoritarian leadership and a troubling moral callousness in light of the epidemic's social and moral consequences - or perhaps because President Bolsonaro has restrained his ministers from acting. As health officials became much more concerned with the treatment of COVID-19 rather than prevention of the spread of the virus, they discussed chloroquine and had come to this conclusion.

The Health Ministry should have adopted Vietnam's approach of isolating those with potential exposure to disease while identifying people who have already been infected. Massachusetts has created a network of public health workers to limit the virus's spread. The country of Brazil has developed a similar program in which community health agents are in charge of keeping tabs on diseases and risk areas in communities. It may, however, play a big role in containing the coronavirus if the Ministry of Health adopts the program and starts using it.

You'll also need to understand Brazilian demographics to explain the virus's high transmission rate. Even though Brazil has roads and air travel infrastructure in place, there are some areas that are not sufficiently developed enough to use it to effectively implement precautionary measures, and that have a social isolation of the population. According to WaterAid, nearly 35 million people in Brazil don't have access to clean water, which limits their ability to follow basic hygiene practices, such as washing their hands and staying home when sick. Because of socioeconomic differences between communities, it is impossible for the less fortunate to follow the "stay-at-home" rules.

Brazil's case numbers (COVID-19) show this inequity considering that many people are unable to remain in their homes to avoid the virus. On top of that, the COVID-19 infections have started to spread rapidly in country towns that lack resources and infrastructure, while the country's major cities are gradually easing back into normal operations.

The federal government created a framework for social assistance that allows some of the retired, unemployed, and marginalized citizens to receive aid through a federal program called Cadastro Único Federal. Despite this program, a significant number of Brazilians lack crucial resources. One million people are without electricity in the Amazon region, and a whopping 46 million Brazilians don't have internet access. They face extra difficulties because of the hurdles to receiving benefits such as food stamps and government help, which adds to their hardship (Keith-Jennings et al., 2019).

One significant difficulty is that a lot of Brazilians can pay to implement social distancing measures, but instead are getting their example from the president and refusing to follow any public health recommendations (Malinverni \& Brigagão, 2020). Even as the disease has become more prevalent, many of Bolsonaro's supporters have organized rallies in protest of the country's governors and the Supreme Court - the latter of which opposed Bolsonaro and has used its power to strengthen state and municipal power in Brazil's federalism. There have been public demonstrations in support of the disease containment efforts by local governments, though higher levels of the federal government have spread false information, which is ultimately detrimental to efforts by local governments to contain the epidemic using scientific information and WHO guidelines.

\section{Cultural Approach in Covid-19}


Effective COVID-19 community engagement message relies on cultural relevance. Values that reflect various cultural institutions affect how people identify themselves and how they relate to others. The communication in both the sending and receiving of messages is affected by culture and how it affects language (Bonvillain, 2019). Since messages for mitigation would likely be received better by the minority groups if there is more cultural sensitivity, a prime example would be to be more aware of racial and ethnic minority group experiences in order to be more aware of minority groups' issues.

It is possible to learn lessons from HIV communication about how to draw in more heavily affected communities through targeting multilevel strategies that identify the factors that matter most to them (their social, economic, and gender contexts, among others) while relying on culture to assist them. Zero grazing is an HIV prevention message in Uganda that encourages people in multipartner marriages to have sex with just their spouse by advising that any sexual activity should take place inside the marriage. This was a community-based reaction to the traditional idea that sex happens one-on-one.

Communities with many black and brown members are organizing mass communication for people like them, in order to clarify information and provide cultural context for those who share their cultural values (Jackson et al., 2018; Edrington \& Lee, 2018). Even when facing a terrible epidemic like COVID-19, certain Native American tribes in the United States have developed remedies of their own, and they do so by promoting isolation as well as closing off their territory while still being able to pursue parts of their spirituality. And in light of COVID19 , we need a big step to get communication in our response to where it needs to be, and the best way to do that is to have culture be the middle ground for people who are working on a new product.

The reaction to community involvement depends on culture. Cultural insensitivity may be shown in the COVID-19 example, as well as in communication about Ebola (Airhihenbuwa et al., 2020). Traditional beliefs about death were twisted into fears and myths during the Ebola epidemic in 2014-2015. In the beginning, most traditional teachings worsened the situation. The warnings made the Ebola virus seem deadly. One example of the ads said, "When you have Ebola, you will die." Or, "Don't contact someone who is sick." Due to high rates of deaths caused by malaria and other illnesses in the impoverished nation of Liberia, people there aren't taking the Ebola threat seriously enough to adhere to preventive and treatment guidelines. In the Monrovia slum of West Point, for example, when people attempted to create physical distance from the disease, Ebola, and now COVID-19 (which is spread via physical contact), they found it more difficult to do so due to erosion of the coastline from the last 10 years, which resulted in a loss of $50 \%$ of the land mass, even though the population did not decrease. Structural inequalities emerge when individuals have no other option but to fail in the absence of support to solve context limitations which are beyond the community's control. These are the inequalities in a number of black and brown communities around the world.

Structural measures to mitigate COVID-19 have to be matched with behavior-based initiatives such as washing hands and keeping distance from others to address hand and water-based infections. The hardships of poor and marginalized communities, who take the brunt of the epidemic, are shown in these everyday events. It is, nevertheless, worth knowing that a culture's set of messages about life experience vary from good behaviors which should be encouraged to bad practices which should be addressed

\section{Conclusion}


The danger to the community must be considered at least equal to the risk to individuals when designing message and communication for COVID-19. Scientists should think about the negative results of the scientific community's culture and try to implement a more desirable method of combating disease. To implement different views and the culture of policy and politics, which affect the choice of messaging strategy architecture, further research and assessment are required. Research and assessment on how to effectively communicate risk reduction and empower communities in order to better understand underlying causes of health inequalities and devise methods to help the public work towards bettering their own well-being is important.

\section{References}

Abbink, P., Stephenson, K. E., \& Barouch, D. H. (2018). Zika virus vaccines. Nature Reviews Microbiology, 16(10), 594-600.

Airhihenbuwa, C. O., Iwelunmor, J., Munodawafa, D., Ford, C. L., Oni, T., Agyemang, C., ... \& Okosun, I. (2020). Peer reviewed: culture matters in communicating the global response to COVID-19. Preventing Chronic Disease, 17.

Bentall, R. P., Lloyd, A., Bennett, K., McKay, R., Mason, L., Murphy, J., ... \& Shevlin, M. (2021). Pandemic buying: Testing a psychological model of over-purchasing and panic buying using data from the United Kingdom and the Republic of Ireland during the early phase of the COVID-19 pandemic. PloS one, 16(1), e0246339.

Bin-Nashwan, S. A., \& Al-Daihani, M. (2020). Fundraising campaigns via social media platforms for mitigating the impacts of the COVID-19 epidemic. Journal of Islamic Marketing.

Bonvillain, N. (2019). Language, culture, and communication: The meaning of messages. Rowman \& Littlefield.

Comite, U. (2020). From health care services to healthcare profiling within the COVID-19 emergency: the role of the health quality impact assessment inside the local health unit.

Dunaetz, D. R. (2020). Terror management theory: missiological applications in times of crisis. Practicing hope: Missions in global crises, 181-197.

Edrington, C. L., \& Lee, N. (2018). Tweeting a social movement: Black Lives Matter and its use of Twitter to share information, build community, and promote action. The Journal of Public Interest Communications, 2(2), 289-289.

Jackson, K. T., Burgess, S., Toms, F., \& Cuthbertson, E. L. (2018). Community engagement: Using feedback loops to empower residents and influence systemic change in culturally diverse communities. Global Journal of Community Psychology Practice, 9(2), 1-21.

Keith-Jennings, B., Llobrera, J., \& Dean, S. (2019). Links of the Supplemental Nutrition Assistance Program with food insecurity, poverty, and health: evidence and potential. American journal of public health, 109(12), 1636-1640.

Kumar, Y. (2020). Geopolitics in the era of globalisation: mapping an alternative global future. Taylor \& Francis.

Malinverni, C., \& Brigagão, J. I. M. (2020). COVID-19: scientific arguments, denialism, eugenics, and the construction of the antisocial distancing discourse in Brazil. Frontiers in Communication, 5, 92. 
O'Connor, D. B., Aggleton, J. P., Chakrabarti, B., Cooper, C. L., Creswell, C., Dunsmuir, S., ... \& Armitage, C. J. (2020). Research priorities for the COVID-19 pandemic and beyond: A call to action for psychological science.

Rudan, I. (2020). A cascade of causes that led to the COVID-19 tragedy in Italy and in other European Union countries. Journal of global health, 10(1).

Tavares, F., Santos, E., Diogo, A., \& Ratten, V. (2020). Teleworking in Portuguese communities during the COVID-19 pandemic. Journal of Enterprising Communities: People and Places in the Global Economy 